\title{
Preparation of Novel Complexes Bearing Diphosphine (dppm) Derived from Thiosemicarbazone Palladacycles ${ }^{\dagger}$
}

\author{
Sara Bermúdez-Fernández *, Raquel Diz-Gil, Paula Munín-Cruz, Marcos Rúa-Sueiro, \\ Juan M. Ortigueira and José M. Vila
}

Department of Inorganic Chemistry, University of Santiago de Compostela, Spain

* Correspondence: sarabegona.bermudez@rai.usc.es

+ Presented at the 24th International Electronic Conference on Synthetic Organic Chemistry, 15 November15 December 2020; Available online: https://ecsoc-24.sciforum.net/.

Received: date; Accepted: date; Published: date

\begin{abstract}
The synthesis of palladium cyclometallated compounds with thiosemicarbazone ligands is described, as well as their reactivity with bidentate phosphine ligands. The synthesis of the ligands was carried out by a condensation reaction between a ketone and a thiosemicarbazide. Subsequently, metalation proceeds and the resulting product is reacted with bis(diphenylphosphino)methane (dppm) under the appropriate conditions to yield the compound with monocoordinated diphosphine.
\end{abstract}

Keywords: thiosemicarbazone; palladium; organometallic

\section{Introduction}

Thiosemicarbazones are compounds with the structure shown in Figure 1. They present different modes of coordination and give complexes with a wide spectrum of biological properties, such as antitumor, antifungal or antimicrobial [1].<smiles>[R]C([R])=NNC(=S)N([R])[R]</smiles>

Figure 1. Structure of thiosemicarbazone.

Their applications are one of the main reasons to study this kind of ligands. Among the different organometallic compounds with thiosemicarbazones, palladium(II) and platinum(II) compounds are of special interest because of their square-planar structure [2-4].

Herein, the synthesis of several cyclometallated compounds derived from thiosemicarbazone ligands is presented. The mechanism of metallation was described by Trofimenko [5].

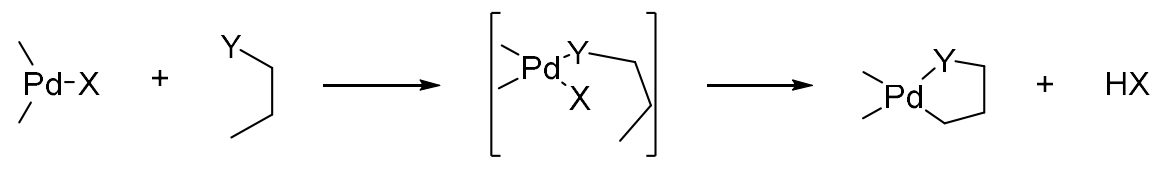

Figure 2. Cyclometallation reaction.

\section{Materials and Methods}




\subsection{Materials and General Methods}

All chemical reagents and solvents were commercial products that were used as received. Elemental analysis of C, H, N, and S were performed in a THERMO FINNIGAN FLASH 1112 analyzer model. IR analyses were recorded in a JASCO FT/IR-4600 spectrophotometer working in the ATR mode. ${ }^{1} \mathrm{H}-\mathrm{NMR}$ and ${ }^{31} \mathrm{P}-\{1 \mathrm{H}\}-\mathrm{NMR}$ were recorded in a Varian Inova 400.

\subsection{Synthesis and Characterization}

\subsubsection{Synthesis of Thiosemicarbazone Ligands}

The thiosemicarbazones were prepared by condensation reactions between a ketone and a thiosemicarbazide and obtained as described in the literature [6] (Scheme 1). The ligands a1-a3 were satisfactorily characterized by elemental analysis, IR, and ${ }^{1} \mathrm{H}-\mathrm{NMR}$.
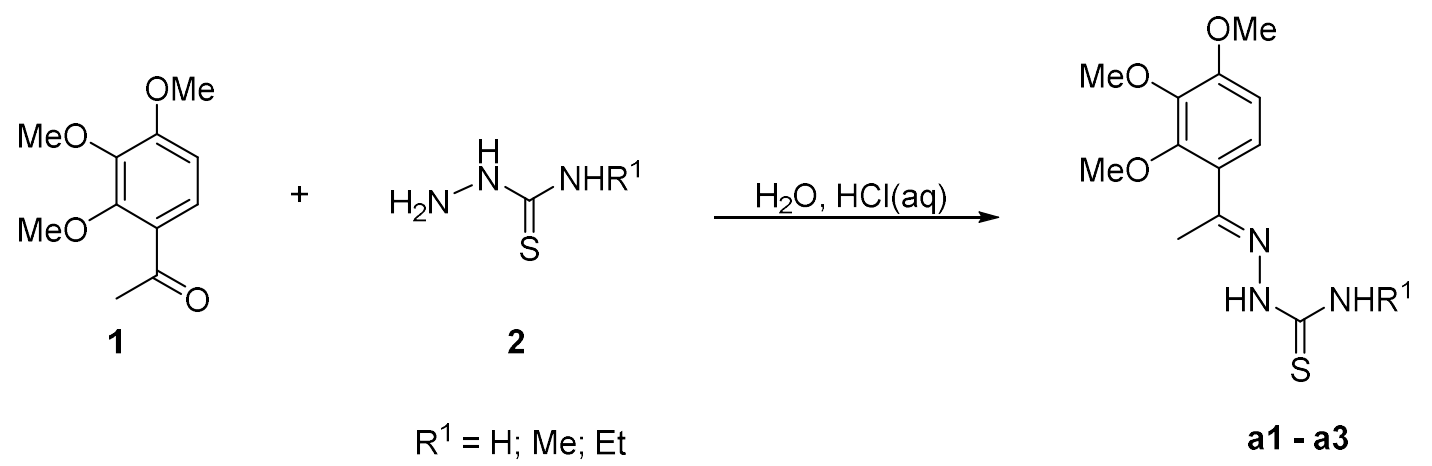

Scheme 1. Synthesis of thiosemicarbazone ligand.

To a solution of thiosemicarbazide (2) $(4,218 \mathrm{mmol})$ in water $\left(40 \mathrm{~cm}^{3}\right) \mathrm{HCl}_{(\mathrm{aq})}$ was added until complete solution. Then, the corresponding amount of ketone (1) $(4,218 \mathrm{mmol})$ was incorporated. The mixture was stirred for $4 \mathrm{~h}$ at room temperature. The white solid formed was collected by filtration and dried under vacuum.

a1: Yield: 95\%. Elemental Anal. Calc. $\mathrm{C}_{12} \mathrm{H}_{17} \mathrm{~N}_{3} \mathrm{O}_{3} \mathrm{~S}$ (283,35): C 50.9, N 14.8, H 6.1, S 11.3\%. Found: C 49.5, N 13.8, H 6.0, S 14.6\%. IR (ATR, $\left.\tilde{v} / \mathrm{cm}^{-1}\right): 826(\mathrm{C}=\mathrm{S}), 1594(\mathrm{C}=\mathrm{N}), 3359,3258,3172(\mathrm{~N}-\mathrm{H}) .{ }^{1} \mathrm{H}-$ NMR (DMSO-d6, $\delta / p p m): ~ 10,13(s, 1 H, N N H), 8,18\left(\mathrm{~s}, 1 \mathrm{H}, \mathrm{NH}_{2}\right), 7,61\left(\mathrm{~s}, 1 \mathrm{H}, \mathrm{NH}_{2}\right), 7,20(\mathrm{~d}, 3 \mathrm{~J}=8,7 \mathrm{~Hz}$, $\left.1 \mathrm{H}, \mathrm{H}^{6}\right), 6,79\left(\mathrm{~d}, 3 \mathrm{~J}=8,8 \mathrm{~Hz} 1 \mathrm{H}, \mathrm{H}^{5}\right), 3,81$ (s, 3H, OMe), 3,78 (s, 3H, OMe), 3,74 (s, 3H, OMe), 2,27 (s, $3 \mathrm{H}, \mathrm{MeCN})$.

a2: Yield: $98 \%$. Elemental Anal. Calc. $\mathrm{C}_{13} \mathrm{H}_{19} \mathrm{~N}_{3} \mathrm{O}_{3} \mathrm{~S}$ (297,37): C 52.5, N 14.1, H 6.4, S 10.8\%. Found: C 52.6, N 13.9, H 6.6, S 10.7\%. IR (ATR, $\left.\tilde{v} / \mathrm{cm}^{-1}\right)$ : 811 (C=S), 1590 (C=N), 3331, 3196 (N-H). ${ }^{1} \mathrm{H}-\mathrm{NMR}$

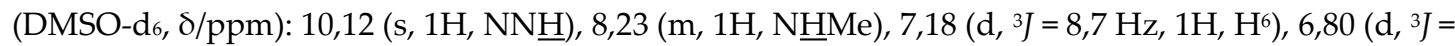

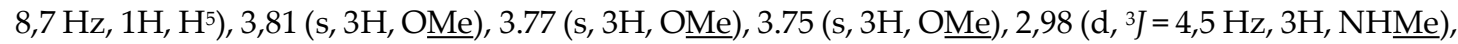
2,22 (s, 3H, $\underline{\mathrm{MeCN}})$.

a3: Yield: 97\%. Elemental Anal. Calc. $\mathrm{C}_{14} \mathrm{H}_{21} \mathrm{~N}_{3} \mathrm{O}_{3} \mathrm{~S}$ (311,40): C 54.0, N 13.5, H 6.8, $\mathrm{S} 10.3 \%$. Found: C 54.2, N 13.5, H 6.9, S 10.6\%. IR (ATR, $\left.\tilde{v} / \mathrm{cm}^{-1}\right): 806$ (C=S), 1592 (C=N), 3345, 3208, (N-H). ${ }^{1} \mathrm{H}-\mathrm{NMR}$

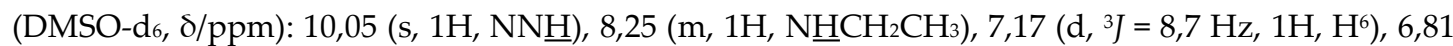
$\left(\mathrm{d},{ }^{3} \mathrm{~J}=8.7 \mathrm{~Hz}, 1 \mathrm{H}, \mathrm{H}^{5}\right), 3,81(\mathrm{~s}, 3 \mathrm{H}, \mathrm{OMe}), 3,78(\mathrm{~s}, 3 \mathrm{H}, \underline{\mathrm{OMe}}), 3,75(\mathrm{~s}, 3 \mathrm{H}, \mathrm{OMe}), 3,64-3,46(\mathrm{~m}, 2 \mathrm{H}$, $\left.\mathrm{NHCH}_{2} \mathrm{CH}_{3}\right), 2,22(\mathrm{~s}, 3 \mathrm{H}, \underline{\mathrm{MeCN}}), 1,11\left(\mathrm{t}, 3 \mathrm{~J}=7,0 \mathrm{~Hz}, 3 \mathrm{H}, \mathrm{NHCH}_{2} \underline{\mathrm{CH}_{3}}\right)$.

\subsubsection{Synthesis of Cyclometallated Compounds}

Cyclometallated compounds (b1-b3) were prepared by reaction of potassium tetrachloropalladate and the corresponding thiosemicarbazone ligand (a1-a3) in ethanol/water. Metallation under these conditions gave the tetranuclear compounds. With the ligand as tridentate $[C, N, S]$ (Scheme 2). The compounds b1-b3 were fully characterized by elemental analysis, IR, and ${ }^{1} \mathrm{H}-\mathrm{NMR}$. 


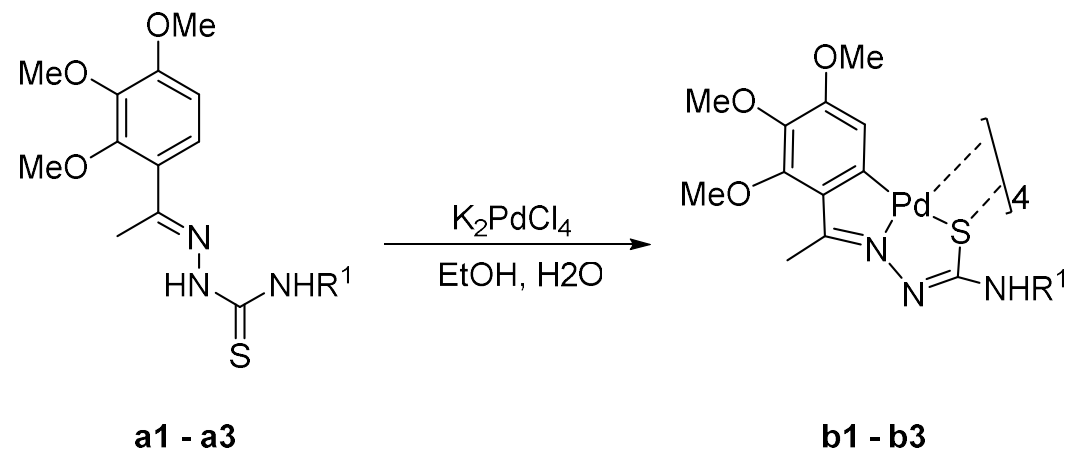

Scheme 2. Synthesis of cyclometallated compounds behavior thiosemicarbazone ligand.

A solution of potassium tetrachloropalladate (II) $(0,7658 \mathrm{mmol}, 0,250 \mathrm{~g})$ in water $\left(7 \mathrm{~cm}^{3}\right)$, was added in ethanol $\left(40 \mathrm{~cm}^{3}\right)$, and a yellow suspension was formed. Then, the thiosemicarbazone ligand (a1-a3) $(0,7659 \mathrm{mmol})$ was incorporated. The mixture was stirred for $24 \mathrm{~h}$ at room temperature. A yellow solid was formed, which was centrifuged and recrystallized from dichloromethane-hexane and dried under vacuum.

b1: Yield: 43\%. Elemental Anal. Calc. [ $\left.\mathrm{C}_{12} \mathrm{H}_{15} \mathrm{~N}_{3} \mathrm{O}_{3} \mathrm{PdS}\right]_{4}(1551,00)$ : C 37.2, N 10.8, H 3.9, S 8.3\%. Found: C 36.3, N 10.0, H 3.9, S 10.3\%. IR (ATR, $\left.\tilde{v} / \mathrm{cm}^{-1}\right)$ : 1579 (C=N), 3319, 3209 (N-H). ${ }^{1} \mathrm{H}-\mathrm{NMR}$

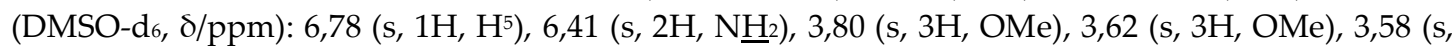
$3 \mathrm{H}, \mathrm{OMe}), 1,92(\mathrm{~s}, 3 \mathrm{H}, \underline{\mathrm{MeCN}})$.

b2: Yield: 48\%. Elemental Anal. Calc. [ $\left.\mathrm{C}_{13} \mathrm{H}_{17} \mathrm{~N}_{3} \mathrm{O}_{3} \mathrm{PdS}\right]_{4}(1607,12)$ : C 38.9, N 10.5, H 4.3, S 8.0\%. Found: C 40.3, N 9.1, H 4.9, S 7.0\%. IR (ATR, v / $\left.\mathrm{cm}^{-1}\right)$ : 1560 (C=N), 3246 (N-H). ${ }^{1} \mathrm{H}-\mathrm{NMR}$ (DMSO-d6,

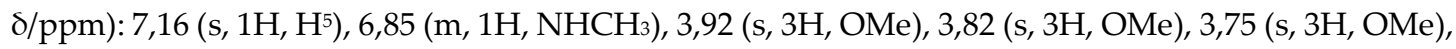
2,00 (s, 3H, MeCN), 1,25 (t, 3j =6,9 Hz, 3H, $\left.\mathrm{NHCH}_{3}\right)$.

b3: Yield: 50\%. Elemental Anal. Calc. [ $\left.\mathrm{C}_{14} \mathrm{H}_{19} \mathrm{~N}_{3} \mathrm{O}_{3} \mathrm{PdS}\right]_{4}(1663,20)$ : C 40.4, N 10.1, H 4.6, S 7.7\%. Found: C 39.8, N 9.9, H 4.6, S 7.0\%. IR (ATR, v $\left./ \mathrm{cm}^{-1}\right): 1558$ (C=N), 3291 (N-H). ${ }^{1} \mathrm{H}-\mathrm{NMR}$ (DMSO-d6,

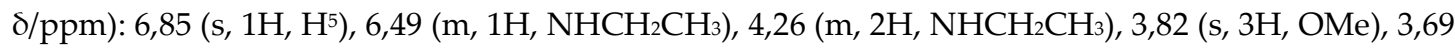
(s, 3H, OMe), 3,59 (s, 3H, OMe), 2,02 (s, 3H, MeCN), 1,10 (m, 3H, $\left.\mathrm{NHCH}_{2} \mathrm{CH}_{3}\right)$.

\subsubsection{Study the Reactivity of Cyclometallated Compound with Diphosphine dppm}

To study the reactivity of these compounds the diphosphine, dppm, was chosen. The reaction was performed according to the literature procedure [7] to give a mononuclear compound (Scheme 3). The compounds c1-c3 were satisfactorily characterized by elemental analysis, ${ }^{1} \mathrm{H}-\mathrm{NMR}$ and ${ }^{31} \mathrm{P}-$ $\left\{{ }^{1} \mathrm{H}\right\}-\mathrm{NMR}$.

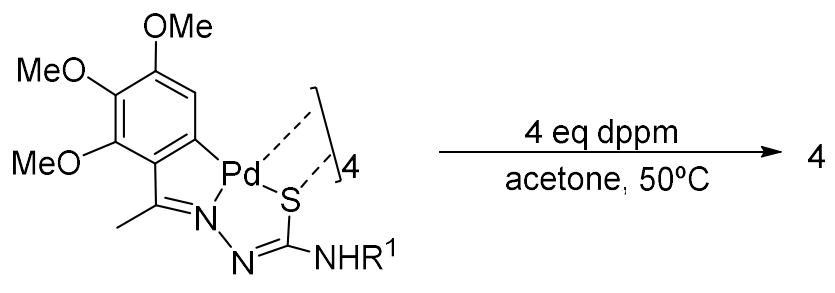

b1 - b3<smiles></smiles>

c1 - c3

Scheme 3. Synthesis of mononuclear cyclometallated compound with dppm ligand.

The phosphine (dppm) (0.1041 mmol, $0.040 \mathrm{~g})$ and the corresponding tetranuclear compound $(0,0260 \mathrm{mmol})$ were added in a flask. Then, 3 vacuum-nitrogen cycles were done. After this, deoxygenated acetone was added $\left(18 \mathrm{~cm}^{3}\right)$, and the mixture stirred at $50{ }^{\circ} \mathrm{C}$ for $4 \mathrm{~h}$. The resulting solution was recrystallized from dichloromethane-hexane and dried under vacuum. 
c1: Yield: $74 \%$. Elemental Anal. Calc. $\mathrm{C}_{37} \mathrm{H}_{37} \mathrm{~N}_{3} \mathrm{O}_{3} \mathrm{P}_{2} \mathrm{PdS}(772,15)$ : C 57.8, N 5.4, H 4.8, S 4.2\%. Found: C 56.4, N 5.3, H 4.6, S 3.3\%. ${ }^{1} \mathrm{H}-\mathrm{NMR}$ (acetone-d6, $\left./ \mathrm{ppm}\right): 7-8$ (m, PPh2), 5,71 (m, 3H, H $\mathrm{H}^{5}$, $\mathrm{NH}_{2}$ ), 3,78 (s, 3H, OMe), 3,61 (s, 3H, OMe), 3,42 (m, 2H, PCH $\left.2 \mathrm{P}\right), 2,96$ (s, 3H, OMe), 2,44 (s, 3H, MeCN). NMR ${ }^{31} \mathrm{P}-\left\{{ }^{1} \mathrm{H}\right\}$ (acetona-d $\left.6, \delta / p p m\right): 27,38\left(\mathrm{~d},{ }^{2} J=88,0 \mathrm{~Hz}, \mathrm{P}^{\mathrm{A}}\right) ;-23,81\left(\mathrm{~d},{ }^{2} J=87,8 \mathrm{~Hz}, \mathrm{P}^{\mathrm{B}}\right)$.

c2: Yield: 73\%. Elemental Anal. Calc. $\mathrm{C}_{38} \mathrm{H}_{39} \mathrm{~N}_{3} \mathrm{O}_{3} \mathrm{P}_{2} \mathrm{PdS}$ (786,18): C 58.1, N 5.3, H 5.0, S 4.1\%. Found: C 59.5, N 5.4, H 5.8, S 3.3\%. ${ }^{1} \mathrm{H}-\mathrm{NMR}$ (acetone-d $\left.6, \mathrm{\delta} / \mathrm{ppm}\right): 7-8$ (m, PPh $), 5,77$ (s, 1H, $\left.\mathrm{NHCH}_{3}\right)$, 5,59 (s, 1H, H5), 3,79 (s, 3H, OMe), 3,59 (s, 3H, OMe), 2,97 (s, 3H, OMe), 3,45 (m, 2H, PCH $2 \mathrm{P}), 3,09$ (sancho, $\left.3 \mathrm{H}, \mathrm{NHCH}_{3}\right), 2,48(\mathrm{~s}, 3 \mathrm{H}, \mathrm{MeCN})$. NMR ${ }^{31} \mathrm{P}-\left\{{ }^{1} \mathrm{H}\right\}$ (acetona-d6, $\left./ \mathrm{ppm}\right): 27,84\left(\mathrm{~d},{ }^{2} \mathrm{~J}=91,2 \mathrm{~Hz}\right.$, $\left.\mathrm{PA}^{\mathrm{A}}\right) ;-23,79\left(\mathrm{~d},{ }^{2} \mathrm{~J}=78,0 \mathrm{~Hz}, \mathrm{P}^{\mathrm{B}}\right)$.

c3: Yield: 82\%. Elemental Anal. Calc. $\mathrm{C}_{39} \mathrm{H}_{41} \mathrm{~N}_{3} \mathrm{O}_{3} \mathrm{P}_{2} \mathrm{PdS}(800,20)$ : C 58.5, N 5.3, H 5.2, S 4.0\%. Found: C 60.6, N 4.7, H 5.0, S 3.5\%. ${ }^{1} \mathrm{H}-\mathrm{NMR}$ (acetone-d6, $\left./ \mathrm{ppm}\right): 7-8$ (m, PPh2), 5,70 (s, 1H, $\left.\mathrm{NHCH}_{2} \mathrm{CH}_{3}\right), 5,58$ (s, 1H, H5), 3,83 (s, 3H, OMe), 3,62 (s, 3H, OMe), 3,49 (m, 2H, PCH $\left.2 \mathrm{P}\right), 3,15(\mathrm{~m}, 2 \mathrm{H}$, $\left.\mathrm{NHCH}_{2} \mathrm{CH}_{3}\right)$ 3,02 (s, 3H, OMe), 2,52 (s, 3H, MeCN), 1,17 (m, 3H, NHCH $\left.\mathrm{CH}_{3}\right) . \mathrm{NMR}{ }^{31} \mathrm{P}-\left\{{ }^{1} \mathrm{H}\right\}$ (acetona-d6, $\delta / \mathrm{ppm}): 27,38\left(\mathrm{~d},{ }^{2} J=92,9 \mathrm{~Hz}, \mathrm{P}^{\mathrm{A}}\right),-23,81\left(\mathrm{~d},{ }^{2} J=92,3 \mathrm{~Hz}, \mathrm{P}^{\mathrm{B}}\right)$.

\section{Results and Discussion}

\subsection{Thiosemicarbazone Ligands (a1-a3)}

The conformational isomer $E$ was mainly obtained in the compounds a1-a3; this may be due to intramolecular hydrogen bridging interactions between the iminic group and the thioamidic group [8].

The ${ }^{1} \mathrm{H}-\mathrm{NMR}$ spectrum for a1 shows the NNH proton resonance as a singlet ca. $10 \mathrm{ppm}$. The NHR' resonance was a broad signal ca. $8 \mathrm{ppm}$. For a2 and $\mathbf{a} 3$, singlets $(1 \mathrm{H})$ were observed and also two singlets for a1. The $\mathrm{H}^{5} / \mathrm{H}^{6}$ signals ( $\mathrm{AB}$ spin system) were correctly assigned ca. 7 ppm. Three singlets were assigned to the $\mathrm{MeO}$ resonances ca. $3.5 \mathrm{ppm}$. The MeCN group showed a singlet ca. 2.3 ppm. The remaining methyl and ethyl groups signals were assigned accordingly.

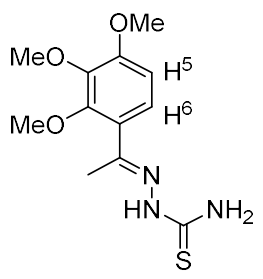

a1

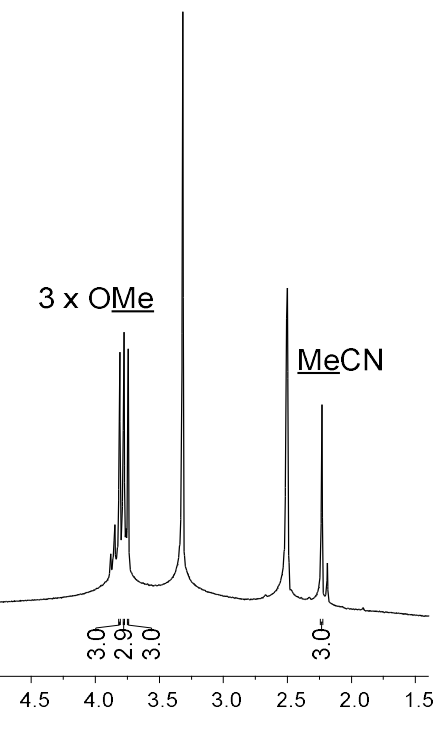

Figure 3. ${ }^{1} \mathrm{H}-\mathrm{NMR}$ spectrum $\left(400 \mathrm{MHz}, \mathrm{DMSO}-\mathrm{d}_{6}\right)$ of the compound (a1). 


\subsection{Discussion for Cyclometallated Compounds (b1-b3)}

The most significant changes on going from the ligand spectra to those of the complexes b1, b2 and b3, was the absence of the $\mathrm{AB}$ spin system resonances. Only a singlet assigned to $\mathrm{H}^{5}$ was observed. The remaining resonances showed slight variations from the parent spectra for a1-a3.

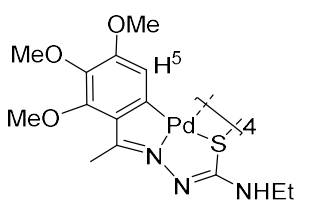

b3

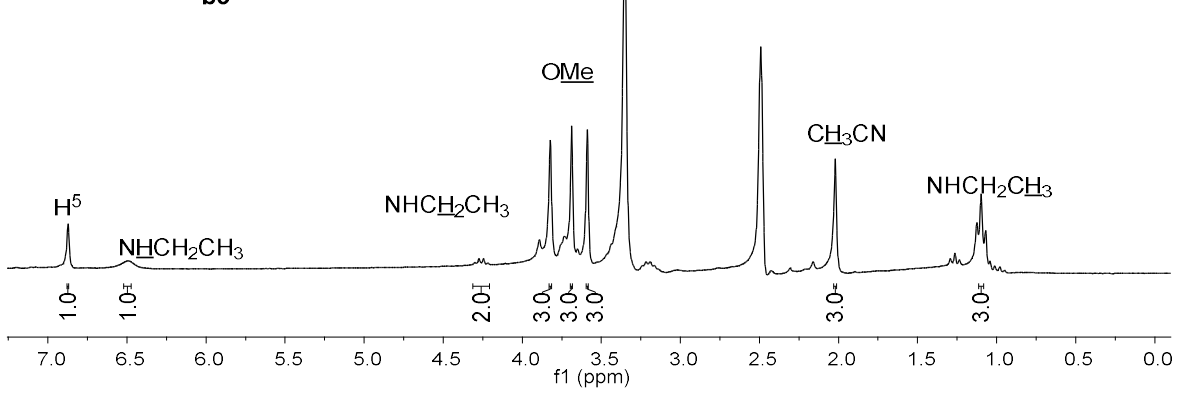

Figure 4. ${ }^{1} \mathrm{H}-\mathrm{NMR}$ spectrum $(400 \mathrm{MHz}$, DMSO-d6) of the compound (b3).

\subsection{Discussion for Cyclometallated Compounds with Diphosphine Ligands (c1-c3)}

The ${ }^{1} \mathrm{H}-\mathrm{NMR}$ spectra for c1-c3 show the resonances for the protons from the starting material and they were correctly assigned. Shielding by the phosphine phenyl ring shifts the $\mathrm{H}^{5}$ and $\mathrm{NHR}^{\prime}$ signals to highfield ca. $5.8 \mathrm{ppm}$. This shielding also affects the C4-MeO group, its signed appears ca. $2.5 \mathrm{ppm}$. The $\left(\mathrm{PPh}_{2} \mathrm{CH}_{2} \mathrm{PPh}_{2}\right)$ resonance was a multiplet in agreement with a complex $\mathrm{AA}^{\prime} X \mathrm{X}^{\prime}$ pattern.

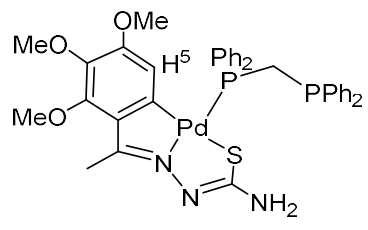

c1

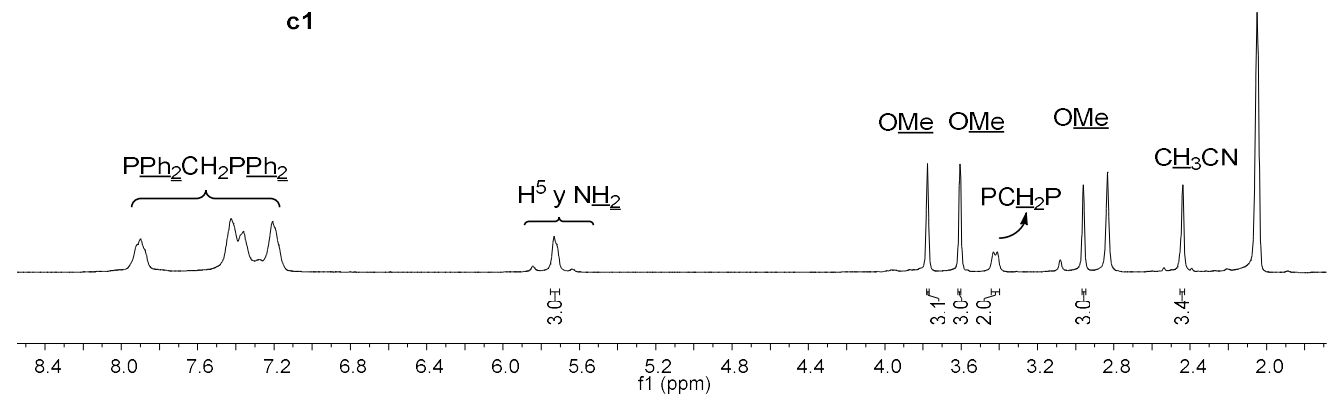

Figure 5. ${ }^{1} \mathrm{H}-\mathrm{NMR}$ spectrum $\left(400 \mathrm{MHz}\right.$, acetone- $\left.\mathrm{d}_{6}\right)$ of the compound (c1).

\section{Conclusions}

The thiosemicarbazone ligands have been synthesized following the procedure described in the literature and were obtained as the $E$ isomer.

The cyclopalladated compounds have been synthesized and they were obtained as tetranuclear species.

Reaction with the diphosphine dppm gave the mononuclear compound in all cases. 
Conflicts of Interest: The authors declare no conflict of interest.

\section{References}

1. Munikumari: G.; Konakanchi, R. Palladium (II) complexes of 5-substituted isatin thiosemicarbazones: Synthesis, spectroscopic characterization, biological evaluation and in silico docking studies. Synth. Commun. 2019, 49, 146-158.

2. Prajapati, N.P.; Patel, H.D. Novel thiosemicarbazone derivatives and their metal complexes: Recent development. Synth. Commun. 2019, 49, 2767-2804.

3. Özerkan, D.; Ertik, O. Novel palladium (II) complexes with tetradentate thiosemicarbazones. Synthesis, characterization, in vitro cytotoxicity and xanthine oxidase inhibition. Investig. New Drugs 2019, 37, 11871197.

4. Lobana, T.S. Activation of C-H bonds of thiosemicarbazones by transition metals: Synthesis, structures and importance of cyclometallated compounds. RSC Adv. 2015, 47, 37231-37274.

5. Fernández-Figueiras, A.; Lucio-Martínez, F. From Chemical Serendipity to Translational Chemistry: New Findings in the Reactivity of Palladacycles. ChemistryOpen 2018, 7, 754-763.

6. Munín, P.; Lucio, F. Study, Preparation and Characterization of Thiosemicarbazone Ligands and Their Compounds; 2016.

7. Martínez, J.; Cabaleiro-Lago, E.M. Synthesis and reactivity of thiosemicarbazone palladacycles. Crystal structure analysis and theoretical calculations. Inorg. Chim. Acta 2016, 449, 20-30.

8. Munín, P. Ph.D. Thesis, 2019.

Publisher's Note: MDPI stays neutral with regard to jurisdictional claims in published maps and institutional affiliations.

(C) 2020 by the authors. Submitted for possible open access publication under the terms and conditions of the Creative Commons Attribution (CC BY) license (http://creativecommons.org/licenses/by/4.0/). 